\title{
O Private Label e Seu Estímulo à Cópia na Indústria de Confecção de Vestuário: uma reflexão a partir de um estudo de caso
}

\author{
Private Label and Its Role on Spreading Copying Habits Towards the Fashion Industry: a \\ reflection over a study case
}

\author{
EMÍDIO, Lucimar de Fátima Bilmaia \\ Mestre; Universidade Estadual de Londrina \\ lucimaremidio@gmail.br \\ SABIONI, Maria Lívia \\ Especialista; Universidade Estadual de Londrina \\ liviasabioni@gmail.com
}

\begin{abstract}
Resumo
O presente trabalho aborda a influência do modelo de gestão conhecido como Private Label no fomento à cópia na Indústria de Confecção de Vestuário, tendo como base para esta reflexão, um estudo de caso desenvolvido em uma empresa cujos métodos são similares aos mencionados. Descreve os procedimentos comuns às indústrias que utilizam a cópia como principal ferramenta de desenvolvimento de produto e o endosso de grandes marcas a essa forma de produção, submetendo tais constatações à análise crítica lastreada em bibliografia relacionada ao tema.
\end{abstract}

Palavras Chave: Private Label; Indústria do Vestuário; Cópia.

\begin{abstract}
The current work aims to approach the influence of the business model known as Private Label on triggering copy habits inside the Fashion Industry, establishing grounds for reflection over a study case developed upon a working experience on a company whose methods can be equaled to those aforementioned. The author describes actions commonly observed on industries that use copying as their main tool on product development and the incitement major labels offer on this form of production, later submitting this findings to critical analysis based on subject-related literature.
\end{abstract}

Keywords: Private Label; Fashion Industry; Copying.

\section{A Indústria de Confecção: uma contextualização}

Em razão do colapso econômico e industrial vivido pelos países envolvidos na Segunda Guerra Mundial, os anos subseqüentes ao fim desse período presenciaram o recrudescimento da demanda de bens de consumo, reavivando diversos setores industriais que haviam enfrentado a estagnação econômica.

A tecnologia de confecção passa, após os anos de 1945, pela sua maior mudança de paradigma desde a I Revolução Industrial. Surgiu, nessa época, o ready-to-wear. A expressão, traduzida posteriormente para prêt-à-porter, foi, segundo Braga (2004, p. 81), 
"uma nova maneira de produzir roupas em escala industrial, com qualidade, com expressão de moda e numeração variada de um mesmo modelo, otimizando, em vários aspectos, o processo de produção industrial do vestuário."

No pós-guerra, as sociedades foram aos poucos se reestabilizando e gradativamente aumentando a qualidade de vida da população. Em razão destes eventos, juntamente com a consolidação das demais indústrias (advento dos eletrodomésticos, popularização da televisão, entre outros), houve um crescimento do poder de compra da sociedade. A indústria do vestuário teve sua visibilidade amplificada pela propagação crescente dos meios de comunicação, tais como cinema, música e televisão, afirmando-se assim como um segmento industrial de relevo.

Já no Brasil, a indústria do vestuário desenvolveu-se de maneira diversa. Em razão da colonização protagonizada pelos portugueses, antes mesmo da Primeira Guerra Mundial o país já dispunha de um desenvolvido parque têxtil, que se consolidou durante esses anos, abastecendo com matéria-prima os países envolvidos. Após o termino da Primeira Guerra, a tecnologia industrial se desenvolveu fortemente nos países europeus e nos EUA, decaindo assim os lucros das indústrias têxteis brasileiras. Porém, com a chegada da crise de 1929, as indústrias nacionais obtiveram nova oportunidade de crescimento.

Após o fim das guerras e com o constante progresso industrial estrangeiro, o desenvolvimento tecnológico das indústrias têxteis brasileiras estagnou-se, transformando o parque industrial brasileiro em um conjunto de maquinários obsoletos. Contudo, o crescimento contínuo do universo da moda exigiu significativas reformulações na estrutura das indústrias nacionais. Investimentos foram feitos em equipamentos avançados, e acrescidos da necessária reformulação da filosofia e dos princípios industriais.

\footnotetext{
Passamos a comprar equipamentos que também contemplavam a segurança do trabalhador, não apenas a segurança em si, mas também a poluição interna da fábrica, principalmente a poluição sonora, um dos principais problemas da indústria têxtil mais antiga. Os equipamentos não são tão barulhentos como antes. As fábricas tinham muito mais máquinas porque o processo de fabricação era mais longo. Hoje as máquinas são mais compactas e encurtam o processo. Para obter o mesmo quilo de fio no final, você tem menos máquinas que produzem muito mais. Também ocorreu diminuição de pessoas expostas ao processo fabril. Em 1990, havia pelo menos um milhão a mais de trabalhadores do que hoje. (NAPOLI, 2007, p. 9)
}

Percebe-se em todos os setores uma grande preocupação quanto ao aprimoramento e à capacitação dos recursos para flexibilizar e dinamizar as ações dos processos de desenvolvimento, fabricação, distribuição e comercialização dos produtos industrializados.

Para Moreira (2007), além da importância histórica no processo de industrialização brasileira, as indústrias que compõem as cadeias de produção do vestuário são importantes para a estrutura industrial do país, entre outras razões, pela sua capacidade de geração de empregos.

Várias são as propostas de organização empresarial neste segmento. O contexto contemporâneo tem motivado a estáveis desafios e o mercado do vestuário, por diferentes motivos, sobretudo econômicos, está apontando para uma produção massificada que tem como característica a reprodução de produtos já concebidos. 
Neste contexto, este trabalho aborda o modelo de gestão conhecido como Private Label (produção licenciada para terceiros por uma marca própria), por meio do qual as empresas, visando enfrentar a competitividade, vêm contribuindo no fomento à cópia de produtos de vestuário de moda. Pautado em revisão bibliográfica sobre o assunto e em um estudo de caso busca refletir sobre os procedimentos comuns às indústrias que utilizam a cópia como principal ferramenta de desenvolvimento de produto e o endosso de grandes marcas a essa forma de produção.

\section{Terceirização: uma metodologia estratégica em prol da competitividade das empresas}

A terceirização desenvolveu-se nos EUA simultaneamente à Segunda Guerra mundial, porém ganhou força e tornou-se mais influente no período do pós-guerra.

O processo consiste em designar a terceiros, detentores de tecnologia mais especializada, uma parte das atividades contidas no processo (atividades estas que não fazem parte do objetivo principal da empresa). Inicialmente, esse modelo de gestão tinha unicamente o objetivo de agilizar os sistemas produtivos de determinado produto. Porém, com o êxito do processo, este se incorporou às fabricas e aos estudos dos especialistas, tornando-se uma metodologia estratégica a fim de reduzir custos, aumentar a produtividade e qualidade dos serviços - interferindo, conseqüentemente, no resultado do produto final.

No Brasil, o sistema foi implantado juntamente com a chegada das empresas multinacionais na década de 1980 e, desde então, tem sido utilizado de maneira eficiente por empresas que têm como objetivo, segundo Queiroz (1998, p. 29), "melhorarem as suas operações, tornando-as mais eficientes nos processos e com mais eficácia nos resultados, ganhando competitividade e otimização econômica, flexibilizando as suas atividades no sentido da agilidade, e da satisfação do mercado."

O processo de terceirização tem como premissa a noção de que a empresa não precisa se especializar em todos os processos necessários para o desenvolvimento de um produto. É possível reduzir gastos e transferir a etapa em questão a empresas que já possuem experiência no referido processo.

Desta maneira, diminuem-se os custos de mão-de-obra especializada, aquisição e manutenção de maquinário, matérias-primas, entre outros. O sistema de terceirização propicia também agilidade no processo produtivo como um todo, sendo que a empresa contratada efetuará o processo com maior facilidade, menor tempo e maior qualidade, possibilitando que a empresa contratante possa concentrar seus recursos em questões pertinentes ao seu desenvolvimento e investir tempo e dinheiro na área em que realmente é especialista, tornando o produto mais competitivo e com maior qualidade.

Em uma abordagem baseada na utilização da terceirização como opção de vantagens competitivas firmadas na melhoria da eficiência operacional, Cabral (2004) apresenta no Quadro 1, a seguir, alguns benefícios decorrentes da terceirização sob as seguintes perspectivas: econômica contábil; competências essenciais; eficiência operacional e custos de transação. 


\begin{tabular}{|l|l|}
\hline Perspectivas & Fatores estimuladores \\
\hline Econômica Contábil & $\begin{array}{l}\text { Transformação de custos fixos em variáveis; } \\
\text { Disponibilização de recursos financeiros. }\end{array}$ \\
\hline Competências essenciais & Foco sobre a atividade-fim da empresa. \\
\hline Eficiência operacional & $\begin{array}{l}\text { Maior flexibilidade de produção; } \\
\text { Acesso às melhores tecnologias disponíveis. }\end{array}$ \\
\hline Custos de transação & $\begin{array}{l}\text { Melhor eficiência por meio da escolha da forma } \\
\text { organizacional adequada à redução dos custos de } \\
\text { transação. }\end{array}$ \\
\hline
\end{tabular}

Quadro 1 - Alguns benefícios decorrentes da terceirização.

Fonte: Cabral (2004)

No entanto, de acordo com Giosa (1993, p. 35), "a terceirização só ira dar certo se as empresas contratantes tiverem ao seu lado, prestadoras de serviços totalmente aliadas e integradas às suas necessidades."

Uma das maiores dificuldades enfrentadas no processo de terceirização é o fato de, muitas vezes, não haver parceria e responsabilidade por parte das empresas contratadas, podendo essas desempenharem um processo de má qualidade interferindo negativamente na proposta inicial. Assim, fica comprometido o êxito do produto final.

Para que isso não ocorra, contratante e contratado devem estabelecer uma sólida parceria. Para Queiroz (1998, p. 113), sem o compromisso do parceiro, "o tomador não consegue implantar e nem desenvolver um processo de terceirização eficaz e eficiente que venha a atender às suas necessidades, e nem chegará a obter ganhos esperados de qualidade, especialidade, agilidade, simplicidade e flexibilidade empresarial." O autor conclui afirmando que "a parceria é a essência da terceirização."

No que se refere ao setor têxtil e de vestuário, em razão de modificações estruturais nas regras sobre importação e exportação, o quadro se transforma drasticamente. Segundo Araújo, Neves e Neves (2008, p. 165), "o setor sofreu alterações profundas com a abolição das restrições quantitativas, que limitam as importações de certos produtos têxteis e vestuário a cotas específicas, ficando sujeito às regras de importação e exportação de qualquer outro setor industrial."

Apesar de haver casos em que se adota o modelo de terceirização na busca de garantias de produtividade, qualidade e competitividade, por meio da transferência tecnológica, esta adoção é habitualmente motivada por um aspecto predatório,

\begin{abstract}
pois, ao se constituir como uma das formas de descentralização mais rentáveis para os empresários brasileiros - especialmente por ter se difundido no país a externalização voltada para a redução de gastos -, ela representa para os diversos setores industriais um instrumento de competitividade baseado no rebaixamento dos custos. Contudo, a transferência dos gastos para as terceiras tem provocado um processo de precarização das condições de trabalho, de deterioração das condições de saúde dos trabalhadores, de progressiva redução de salários e dos benefícios, de intensificação do ritmo de trabalho, além de contribuir para o enfraquecimento dos sindicatos. (AMORIM, 2003, p. 42-3)
\end{abstract}

A indústria de confecção utiliza-se amplamente de trabalho terceirizado, especialmente por motivos relacionados ao custo da empresa, que passa a concentrar os esforços nas suas atividades estratégicas. Apresenta-se a seguir um estudo de caso, realizado em uma empresa especialista no processo de Private Label. 


\section{Empresa X, Especialista no Processo de Private Label: um estudo de caso}

O estudo de caso em questão refere-se à empresa, denominada neste trabalho, como empresa X. Fundada em 1989, consolidou-se no mercado de jeans wear como hábil especialista no processo de Private Label. Atualmente tem aproximadamente 15 mil metros de área construída, dispõe de 600 colaboradores e uma capacidade produtiva de 150 mil peças por mês.

Os processos produtivos, com poucas exceções, são realizados na própria empresa, quais sejam: a criação (pesquisa e desenvolvimento); modelagem; risco e corte; costura; lavanderia; tinturaria; estamparia; bordado; acabamento e expedição. A empresa terceiriza processos como alguns tipos de bordados diferenciados (couro, detalhes com corte a laser, paetês).

Visando proporcionar o suporte necessário aos clientes para quem trabalha, e por atender a marcas conceituadas nacional e internacionalmente, a empresa $X$ investe fortemente em pesquisas de tendências realizadas pelo seu departamento de desenvolvimento de produto ao menos quatro vezes ao ano, visitando países onde o conceito de moda como formadora de opinião já é consolidado.

Nestas viagens buscam-se por novidades, lavagens diferenciadas, modelos atuais e estilos "em voga". A pesquisa não é conceitual, ou seja, não tem o intuito de detectar comportamentos, idéias ou estilos de vida em ascensão. Ela é, sim, focada em produtos, modelos, peças e lavagens já desenvolvidas por marcas estrangeiras conceituadas no segmento jeans wear. Na viagem, compram-se e fotografam-se peças, geralmente nos provadores das lojas das marcas, a fim de demonstrar aos clientes o que foi visto na pesquisa.

Alguns estilistas das marcas próprias contratantes dos serviços da empresa $X$ entregam seus rascunhos (desenho das peças a serem feitas) bem definidos, com a escolha prévia dos tecidos e dos diversos insumos necessários para a produção da primeira peça. Porém, a maioria dos clientes prefere a opção dada pela empresa $X$, de ter seus produtos "criados" por sua equipe de desenvolvimento; neste caso, geralmente não é determinado pelos contratantes às especificações de linha, modelo, tecido ou mesmo lavagem.

Além de executar as funções acima, bem como de efetuar os contatos necessários para o esclarecimento de quaisquer outras dúvidas que venham a surgir sobre a execução do produto em questão, o setor de desenvolvimento de produto na referida empresa é o encarregado também pelo desenvolvimento da ficha-técnica, a qual deve dispor das informações necessárias a melhor compreensão do que se propõe confeccionar. Esta deve conter além de todas as informações e especificações para a concepção da primeira peça (denominada como peça-piloto), também o desenho técnico, por meio do qual se possibilita ter uma visualização gráfica do produto pronto.

Para Souza (2006) a ficha técnica é um referencial para integração dos ofícios de concepção e confecção do modelo - o principal veículo de comunicação entre o criador e o profissional modelista na indústria - e sua transformação, de acordo com a seqüência do processo, vai estruturando o produto na medida do seu desenvolvimento e informando aos envolvidos a sua evolução no decorrer do processo.

Segundo Leite e Velloso (2006, p.147) "a ficha técnica deve conter toda a memória descritiva do produto" e para que esta seja elaborada todos os dados têm que ser de conhecimento e estar disponível ao profissional envolvido, e este tem que fornecer uma ficha clara, concisa, dotada de toda a informação necessária, respeitando a quem irá lê-la. 
Por isso, depois de sanadas todas as possíveis dúvidas, a ficha-técnica segue para o setor de modelagem, onde se tem, na maioria das vezes, uma tabela de medidas ou base de modelagem enviada pelo cliente. Segundo Araújo (1996, p. 92), "os modelistas são intérpretes de uma linguagem muito especial, baseada em desenhos e anotações de estilistas" com o objetivo de produzir moldes que depois de montados reproduzam esses desenhos e possuam medidas adequadas. O modelista faz a mediação entre a criação e a produção das peças.

Após, a ficha é repassada ao setor de risco e corte e posteriormente enviada para o setor de pilotagem, onde a peça é costurada e as eventuais dúvidas entre a costura e a modelagem são esclarecidas.

Depois de ser costurada a peça é enviada à lavanderia, onde passa por vários processos químicos e artesanais a fim de deixá-la com o visual determinado pelo cliente. Muitas das lavagens não são desenvolvidas pela empresa $X$; nesse caso, são usadas como padrão de lavanderia as peças importadas, imagens de catálogos de outras marcas e fotos tiradas em lojas do segmento jeans wear durante a rota de viagem de pesquisa de tendências.

Assim que a peça piloto é aprovada na lavanderia, ou seja, está igual ou muito próxima do que já havia sido requisitado pelo cliente (ou escolhido pelo setor de desenvolvimento de produto da empresa X), a mesma retorna ao núcleo de modelagem onde são tiradas as medidas para verificar se o seu tamanho e proporção estão compatíveis com a tabela envida pelo cliente. Se as medidas estiverem aprovadas, a tabela e a peça seguem para o acabamento onde é realizada a remoção do excesso de linhas e a aplicação dos rebites, botões e etiquetas conforme o pré-estabelecido pelo cliente em seus rascunhos. Feito isso, a peça é finalmente expedida ao contratante.

De posse da peça piloto, o cliente (estilista responsável pela marca) faz a prova da mesma e quando necessário, redige anotações sobre possíveis ajustes referentes:

- A modelagem (quando não se atinge as medidas desejadas);

- Ao modelo (quando algum detalhe do modelo da peça não fica de acordo com o imaginado anteriormente pelo estilista, ou quando se tem a intenção de diminuir processos na produção e conseqüentemente diminuir o custo da peça);

- A lavanderia (quando, por motivos estéticos ou de custo se elimina ou se modifica algumas das etapas da lavagem);

- Até mesmo de insumos, pois, muitas vezes, por questões de preço, as peças têm seus tecidos, linhas, forros, entre outros, alterados por produtos mais baratos ou mais acessíveis.

A partir das alterações propostas é realizada uma segunda peça, denominada repilotagem ou repiloto. Contudo, em função do curto prazo, muitas vezes as alterações são feitas diretamente nos produtos do mostruário do cliente. É importante lembrar que de acordo com Escorel (199, p. 66) "o modo industrial de produção não permite ajustes no processo de fabricação. No momento em que a matriz é levada para a linha de produção, não há mais retorno possível, a não ser que se refaça a matriz".

O mostruário, ou show room, é um espaço que tem como finalidade a apresentação de produtos à venda, que serão oferecidos aos seus compradores (empresários e lojistas). Depois de finalizada a exposição e as vendas dos produtos no show room, a marca contratante faz a encomenda da quantidade necessária a ser produzida em escala industrial.

Para que as peças sejam entregues aos lojistas e empresários que as compraram, estas devem ser idênticas aquelas vendidas nos mostruários. Ressalta-se que por meio do 
sistema de Private Label, muitas empresas produzem peças para grandes grifes nacionais e até internacionais. Utilizando-se deste sistema entrega-se a peça pronta com a etiqueta da marca do cliente contratante, diferente do processo de facção, no qual o cliente dá a matéria-prima e os aviamentos e só utiliza a mão-de-obra da empresa contratada.

\section{O Desenvolvimento de Produtos Para Private Label: a cópia na contramão do design de moda}

De acordo com Capelassi (2010), o processo de desenvolvimento de produto pode ser definido como um conjunto de atividades, envolvendo quase todos os departamentos da empresa, que tem a finalidade de lançar novos produtos, transformando as necessidades de mercado em produtos ou serviços economicamente viáveis. O processo se inicia com a tomada de decisões estratégicas pela administração da empresa, e engloba o projeto do produto e a parte fabril, chegando ao consumidor final.

A indústria de confecção tem sua estrutura fundamentada na criação, produção e comercialização de produtos. "Ao processo de definição, criação, estudo de viabilidades e

métodos para produção damos o nome de desenvolvimento de produto". (TREPTOW, 2003). Para Sanches (2008) nas esferas do design, o termo desenvolvimento de produto considera o trajeto que inclui desde o planejamento da concepção até o descarte desses objetos.

Montemezzo (2003) descreve no Quadro 2, a seguir, as etapas do desenvolvimento de produto de moda/vestuário nas indústrias que trabalham com marca própria. Trata-se de uma síntese das reflexões de vários autores estudados pela autora. As etapas destacadas são aquelas nas quais o Designer está diretamente envolvido, salientando que a participação nas ações anteriores e o acompanhamento das posteriores garantem a qualidade do projeto:

\begin{tabular}{|c|c|}
\hline Etapas & Ações \\
\hline \multirow[t]{5}{*}{ Planejamento } & Percepção do mercado e descoberta de oportunidades \\
\hline & Análises / expectativas e histórico comercial da empresa \\
\hline & Idéias p/produtos/Identificação do problema de design \\
\hline & $\begin{array}{l}\text { Definição de estratégias de marketing, desenvolvimento, produção, } \\
\text { distribuição e vendas. }\end{array}$ \\
\hline & Definição do cronograma \\
\hline \multirow[t]{4}{*}{ Especificação do projeto } & Análise e definição do problema de design (diretrizes) \\
\hline & Síntese do Universo do consumidor (físico e psicológico) \\
\hline & Pesquisa de conteúdo de moda (tendências) \\
\hline & Delimitação do projeto (objetivos) \\
\hline \multirow[t]{2}{*}{ Delimitação Conceitual } & Geração de conceitos e definição do Conceito Gerador \\
\hline & Definição de princípios funcionais e de estilo \\
\hline \multirow[t]{2}{*}{ Geração de alternativas } & $\begin{array}{l}\text { Geração de alternativas de solução do problema } \\
\text { (esboços/desenhos, estudos de modelos). }\end{array}$ \\
\hline & Definições de configuração, materiais e tecnologias \\
\hline \multirow[t]{5}{*}{ Avaliação e Elaboração } & Seleção da(s) melhor (es) alternativa(s) \\
\hline & Detalhamento de configuração (desenho técnico) \\
\hline & Desenvolvimento de ficha técnica, modelagem e protótipo \\
\hline & Testes ergonômicos e de usabilidade \\
\hline & Correções/adequações \\
\hline
\end{tabular}




\begin{tabular}{|l|l|}
\hline Realização & Avaliações técnicas e comerciais apuradas \\
\cline { 2 - 3 } & Correções/adequações \\
\cline { 2 - 3 } & graduação da modelagem \\
\hline & $\begin{array}{l}\text { Confecção de Ficha técnica definitiva e Peça piloto (aprovação técnica e } \\
\text { comercial do(s) produto(s)) }\end{array}$ \\
\hline & aquisição de matéria prima e aviamentos \\
\hline orientação dos setores de produção e vendas \\
\hline & definição de embalagens e material de divulgação \\
\hline & produção \\
\cline { 2 - 3 } & lançamento do(s) produto(s) \\
\hline
\end{tabular}

Quadro 2 - Desenvolvimento de produtos de moda/vestuário.

Fonte: Montemezzo (2003)

A autora esclarece que a opção de plural, acrescida à palavra produto, justifica-se em razão de uma característica das indústrias de vestuário, visto que estas indústrias geralmente lançam simultaneamente um conjunto integrado de produtos (coleção), oferecidos em curtos espaços de tempo.

Segundo Romeiro (2004), a atividade projetual, como compreendida nos dias atuais, é relativamente recente. As demandas cada vez mais sofisticadas por parte dos usuários são as respostas das empresas através da aplicação de metodologias e ferramentas de projeto. Neste contexto, não cabem mais métodos intuitivos ou não estruturados de projeto, mas sim, a aplicação de novos e sofisticados conjuntos de procedimentos para desenvolvimento de produtos.

De acordo com Back et al. (2008), o objetivo do processo metodológico é desenvolver produtos com eficiência e eficácia, e para isso é necessário saber o que fazer, para quem fazer, quando fazer, com que fazer e como fazer. "A esta organização (conhecimentos, métodos e ferramentas utilizadas para o desenvolvimento) chamar-se-á metodologia de projeto, ou metodologia de desenvolvimento de produtos." (BACK et al., 2008, p. 7).

Para Capelassi (2010), o design de moda pode ser considerado como um processo para projetar produtos, considerando que são produzidos industrialmente e num plano produtivo. Dessa forma o profissional precisa estar inteirado das técnicas e pesquisas de mercado, da ergonomia e das técnicas de tratamento de materiais, que the permitirão chegar ao produto final com os requisitos solicitados pelos usuários/consumidores.

A indústria que desenvolve artigos de vestuário com informação de moda é uma indústria muito complexa, pois trabalha com produtos de obsolescência muito rápida, provocando um alto nível de efemeridade dos mesmos, e em conseqüência disso, estabelece um ritmo cíclico e constante de trabalho, bem como um desafio de projetar esses produtos.

De acordo dom Souno (2007) para acompanhar essa dinâmica do setor, é comum o designer adotar alguns recursos, como o aproveitamento de estruturas de peças básicas na concepção de modelos, a fim de atingir o cumprimento de suas tarefas.

Lipovetsky (1989, p. 162) descreve o aproveitamento dessas estruturas afirmando que processo de moda despadroniza os produtos, multiplica as escolhas e opções, manifesta-se em políticas de linhas que consistem em propor um amplo leque de modelos e versões construídos a partir de elementos-padrão e que só se distinguem ao termo da linha de montagem por pequenas diferenças combinatórias.

Neste contexto ressalta-se a constatação freqüente da grande semelhança de materiais, lavagens, modelos e detalhes entre as marcas que, muitas vezes, atingem públicos 
diferentes. Assim, torna-se legítimo questionar a razão de a cópia de modelos, materiais e lavagens, muitas vezes idênticas, seja algo tão constante na produção de moda de grandes marcas, conceituadas e lembradas pela diferenciação e pelo excelente design. É importante salientar que as marcas para as quais a empresa $X$ presta serviços de terceirização são marcas de grande conceituação nos quesitos já mencionados anteriormente.

Ainda a exemplo da empresa $X$, que trabalha como terceirizada de várias marcas próprias (em torno de quarenta marcas), é comum se constatar que uma marca contratante obtenha peças piloto muito próximo, algumas vezes até idêntica às peças de outras empresas concorrentes. Isto acontece porque as fotos, lavagens e modelos utilizados, assim como peças trazidas da viagem de tendências pela empresa contratada são oferecidas para todos os clientes por ela atendidos.

Registros mostram que, em meados da década de 1980, a cópia na moda brasileira era tão explícita que algumas marcas estrangeiras proibiam a entrada de brasileiros em suas apresentações. Para muitos, trata-se de um inconsciente coletivo, de estilistas que absorvem as mesmas influências ou que estão imersos em um mesmo panorama estético.

De acordo com Caldas (2004) é sabido por todos que estilistas e criadores utilizamse freqüentemente de referências e inspirações provenientes de outras épocas, da arte, da arquitetura e que muitas vezes fazem uso das releituras para atingir objetivos estéticos, conceituais ou como forma de viabilizar a idéia de uma proposta. No entanto, a cautela e o respeito aos limites éticos são fundamentais.

O autor ressalta que a falta da pesquisa de verdade, no caminho fácil da cópia travestida de referência, já se anuncia como um erro fatal de empresas e marcas do século XXI. O equivoco é duplo. No que se refere ao indivíduo - que deve ser a finalidade ultima de todo projeto e de toda ação no mercado, consiste em não levar profundamente a serio a promessa de que é preciso conhecer e investigar os comportamentos, embora esta seja uma unanimidade no nível do discurso. Do lado da empresa e da marca, o erro em referenciar-se principalmente pelo mercado, pela concorrência, abandonando a busca de um caminho próprio que poderíamos chamar pelo nome genérico de identidade.

Outra questão ainda a se considerar de acordo com o mesmo autor é a grande dependência dos países centrais, ditos lançadores de tendências. Esta dependência é concreta quando se pensa, por exemplo, na interconexão dos mercados financeiros. Mas o pior é quando ela é simbólica, como acontece com a produção intelectual brasileira (e dos países periféricos) que continuam precisando do aval do circuito acadêmico norte americano e europeu para obter um carimbo de legitimidade [...] é urgente repensar a questão das referências internacionais.

Conforme estudos do Centro de Design do Paraná, o que mais se faz é "cópia de modelos produzidos nos centros difusores, com adaptações a clima e oferta de matériaprima". Entre os centros difusores tem-se Milão, Paris e Londres e "para manter-se atualizada, as indústrias que desenvolvem produtos de moda estabeleceram uma estratégia para a coleta de informações, incluindo rotas de viagem aos países que mantêm a hegemonia de inovação do setor." (PIRES, 2008, p. 277). Um setor de criação auxiliaria na competitividade dos produtos contratados especialmente pela qualidade e geração de novos mercados, levando a mais uma oportunidade para o crescimento empresarial que se reflete em vários outros setores que integram a fase de produção do vestuário.

Contudo, na contramão de todas estas idéias, há quem defenda que essa intensa cultura de cópias que se presencia atualmente no ramo da moda desencadeia o aparecimento e o estabelecimento das tendências. Segundo Blakley (2010), é em virtude das 
cópias que se empreende a democratização da moda. Isto, somado ao fenômeno fastfashion, transforma-se numa vasta gama de opções ao público-alvo. Faz também com que as tendências globais sejam restabelecidas muito mais rapidamente do que antes, além de induzir a rápida obsolescência dos produtos e das tendências, transformando o universo da cópia em algo lucrativo para o mercado.

Outra conseqüência das cópias, ainda na visão Blakley (2010) é a aceleração na inovação e na criatividade. Os vanguardistas, que não querem aderir à moda vigente, buscam por tendências, estilos e comportamentos que ainda estão por vir. Faz também com que criadores e estilistas busquem por uma assinatura, uma estética coerente, um visual que reflita suas identidades. Assim, caso alguém os plagie, ficará claro que o produto em questão não os pertence.

Assim, a realidade apresentada no contexto da indústria do vestuário de moda, a exemplo do modelo de gestão Private Label, objeto deste estudo, estimula o fomento à cópia ao buscar oferecer produtos integrados à competitividade e velocidade de expansão do segmento que a cada dia se renova.

\section{Considerações Finais}

Dentre os vários setores existentes, vale destacar a moda como um dos campos de maior destaque nos últimos anos. Além de ser uma área para o desenvolvimento e a oportunidade de grandes negócios, ela também surge como fenômeno que interfere nos aspectos históricos, culturais, sociais, econômicos, ambientais e comportamentais da humanidade. Atrelado a isso, a moda ainda é apontada como fonte de imenso potencial para a ciência, chamando a atenção de diversos pesquisadores

A moda desperta o desejo e a necessidade de consumo. De acordo com Lipovetsky (1989), a lógica econômica realmente varreu todo ideal de permanência, é a regra do efêmero que governa a produção e o consumo dos objetos. A temporalidade curta da moda desencadeia um processo de renovação e de obsolescência "programada" propício a revigorar sempre mais o consumo, e com o design industrial, a moda não remete mais apenas aos caprichos dos consumidores, passando a ser uma estrutura constitutiva da produção industrial de massa.

De acordo com Cidreira ( 2005), esta cultura de consumo mundial, apesar dos rótulos e críticas, tem favorecido o crescimento da indústria da moda e áreas associadas, através de uma nova percepção do setor e do fenômeno social e cultural moda, que passou a ser visto como uma área de grandes oportunidades de negócios, desta forma, a área moda, sempre se renovando e se desenvolvendo, tornando-se um grande complexo mundial.

De acordo com Semprini (2010) não se pode compreender o crescimento do poder e a metamorfose da marca contemporânea sem observar sua capacidade de articular e de colocar em relação às três dimensões: o consumo, a comunicação e a economia, visto que a marca esta ao mesmo tempo, profundamente ligada `a esfera do consumo, alimenta-se de comunicação e representa uma manifestação da economia pos-moderna de suma importância.

No entanto de acordo com Capelassi (2010), esse anseio pelo consumo precisa ser expresso por produtos integrantes das coleções, função essa desenvolvida pelo profissional do design de moda, que com conhecimentos teóricos adquiridos nos cursos de formação especifica e vivências diárias, pode colocar em prática nas indústrias de confecção todo o 
seu potencial de construção de produtos, em um processo de melhoria contínua e otimização dos métodos, com foco no desempenho comercial do produto no que diz respeito à moda como mercado.

Para Semprini (2010) o processo de aumento das ofertas de produtos e serviços, já amplamente instalados, continua e intensifica-se. O surgimento de novas tecnologias, a necessidade de encontrar novos mercados e a pressão comercial favorece a criação de novas categorias de produtos. No vestuário as redes de magazines multiplicaram-se e diversificaram-se (Gap, Zara, H\&M). Para o autor parece claro que a tendência a multiplicação quantitativa e qualitativa da oferta só progrediu e continuará provavelmente no mesmo caminho: novos produtos, novas versões entre outros.

O consumidor, porém, estabelece uma distinção muito clara entre as novas ofertas pertinentes, que representam para ele um real interesse, e as ofertas que apresentam só uma utilidade marginal ou diferença imperceptível com relação ao que já conhece. Pela sua própria visibilidade a marca fica muito exposta a esses riscos de desvio.

De acordo com Emidio e Sabioni (2010) no contexto atual dos fenômenos culturais e sociais, o consumo de produtos de moda estabeleceu-se em torno de grandes marcas e tendências unilateralmente impostas. Tais circunstâncias são interpretadas, por indivíduos interessados pela produção em moda, como uma uniformização empobrecedora das opções oferecidas ao consumidor. Para aqueles que não aceitam passivamente a limitação desse universo, restam poucas alternativas dentro do circuito tradicional de compras.

Daí a importância de o design envolver um conjunto de interações entre designer, processos produtivos, mercado consumidor e o produto conforme enfatizado por Montemezzo (2003), para a qual, neste sistema de interações, a relação do designer com o produto, abrange o gerenciamento e controle das situações geradas neste contexto, caracterizando o Processo de Design, que segundo Löbach (2001), é tanto um processo criativo como um processo de solução de problemas.

Para o autor, deste modo, o designer procura desenvolver um produto inovador, dotado de um elevado número de características valorizadas pelo usuário/consumidor. Tal tarefa é baseada na capacidade, deste profissional, de associar determinadas informações com um problema, estabelecendo, através de uma postura crítica, novas relações entre elas e propondo uma solução criativa e eficaz.

Analisando o exposto acima, em conjunto com o que foi ponderado ao longo do trabalho, salientam-se a necessidade de uma reforma pungente e imediata nos vícios, processos e, principalmente na ética vigente nos círculos intelectuais e criadores da moda contemporânea. É evidente que uma legislação adequada poderia contribuir para com as questões aqui levantadas.

Entretanto, na ausência desta, e antecipando a possibilidade de que o advento de formulações jurídicas acerca do tema poderia eventualmente cair à censura, à ineficácia em sua aplicação, enfim, ao destino comum a muitas das leis existentes no país destinadas à regulação da liberdade criativa, é imperativo que esta nova visão surja de dentro da cadeia produtiva da moda.

Tal recomendação serve principalmente às indústrias do segmento, que devem enxergar o respeito aos limites éticos não de maneira imediatista e puramente financeira, como algo que as privaria de novos negócios, mas sim como uma adequação a um futuro em que a qualidade e a exclusividade se desenhariam como um diferencial que atrairia visibilidade e respeito às empresas de confecção de vestuário. 
Barcaro (2008, p.155) corrobora com esta reflexão ao afirmar que "produzir um produto de qualidade, com conteúdos estilísticos originais e materiais cuidadosamente selecionados, já é uma competência comum a muitos concorrentes e, é, portanto, considerado pré-requisito para a competição"

Assim, a necessidade de diferenciação e, conseqüentemente, de fornecer respostas rápidas aos movimentos competitivos dos concorrentes, confrontam as empresas com a necessidade de focalizar o investimento organizacional nas competências dos recursos humanos, detentores do conjunto de conhecimentos, experiências e capacidades para compreender as mudanças necessárias em cada momento, idealizar soluções e implementálas. No caso do design de moda, essa diferenciação é ainda mais exigida, uma vez que a moda contemporânea se caracteriza, dentre outros aspectos, pelo paradoxal desejo de padronizar-se e diferenciar-se do outro, sob a preponderante lógica do individualismo (LIPOVETSKY: 1989).

Assim é necessário que os designers de moda, acadêmicos, críticos e os demais envolvidos na indústria do vestuário postulem as práticas a serem aceitas dentro de um setor de tamanha relevância criativa, cultural e econômica. Os limites éticos, no que tange ao processo de criação, devem ser construídos conjuntamente e visando ao bem comum da categoria. A discussão deve ser ampla, acessível e incluída nos tópicos discutidos na academia, permitindo que uma nova geração saia das universidades e ingresse no mercado difundindo práticas exemplares que permitam a moda brasileira enfim ser reconhecida pelos motivos corretos no exterior.

\section{Referências}

AMORIM, Elaine Regina Aguiar. No limite da precarização?: terceirização e trabalho feminino na indústria de confecção. 2003. 222 f. Dissertação (Mestrado em Sociologia) - Universidade Estadual de Campinas, Campinas, 2003.

ARAÚJO, Mário de. Tecnologia do vestuário. Lisboa: Fundação Calouste Gulbenkian, 1996.

ARAÚJO, Mário; NEVES, Manuela; NEVES, Jorge. O impacto da globalização e do multiculturalismo no design de moda. In: PIRES, Dorotéia Baduy (Org.). Design de moda: olhares diversos. Barueri, SP: Estação das Letras e Cores Editora, 2008.

BACK, Nelson; OGLIARI, André; DIAS, Acires; SILVA, J Jonny Carlos. Projeto integrado de produtos: planejamento, concepção e modelagem. Barueri, SP: Manole, 2008.

BARCARO, Andrea. Os processos de uma empresa de moda. In: SORCINELLI, Paolo (Org.). Estudar a moda: corpos, vestuários, estratégias. São Paulo: Senac São Paulo, 2008. p.143 156.

BLAKLEY, Johanna. Johanna Blakley: lessons from fashion's free culture. Disponível em: <http://www.ted.com/talks/johanna_blakley_lessons_from_fashion_s_free_culture.html>. Acesso em: 21 jul. 2010.

BRAGA, João. História da moda. São Paulo: Anhembi Morumbi, 2004. 
CALDAS, Dario. Observatório de Sinais: teoria e prática da pesquisa de tendências. Rio de Janeiro: Editora Senac Rio, 2004.

CABRAL, Sandro. Analisando a reconfiguração da cadeia de produção de pneus no Brasil pela economia dos custos de transação. Gestão e Produção, São Carlos, v. 11, n.3, p. 373-384, set/dez. 2004.

CAPELASSI, Carla Hidalgo. Metodologia projetual para produtos de moda e a sua interface com as tabelas de medidas do vestuário. Baurú, 2010. 102 f. Dissertação (Mestrado em Desenho Industrial) - Universidade Estadual Paulista.

CIDREIRA, Renata Pitombo. Os sentidos da moda: vestuário, comunicação e cultura. São Paulo: Annablume, 2005.

EMÍDIO, Lucimar de Fátima Bilmaia. SABIONI, Maria Lívia. Brechó e Moda: uma alternativa de projeto para substituir o processo de garimpo de peças do vestuário. In: CONGRESSO NACIONAL DE PESQUISA E DESENVOLVIMENTO EM DESIGN, 9, São Paulo, 2010. Anais... São Paulo: PPG em Design, 2010.

GIOZA, Livio Antônio. Terceirização: uma abordagem estratégica. São Paulo: Pioneira, 1993.

LEITE, A. S.; VELLOSO, M. D. Desenho técnico de roupa feminina. Rio de Janeiro: Senac Nacional, 2006.

LIPOVETSKY, G. O império do efêmero: a moda e seu destino nas sociedades modernas. São Paulo: Companhia das Letras, 1989.

LÖBACH, B. Design industrial: bases para a configuração dos produtos industriais. São Paulo: E. Blucher, 2001.

MONTEMEZZO, Maria Celeste de Fátima. Diretrizes metodologias para o projeto de produtos de moda no âmbito acadêmico. Bauru, 2003. 97f. Dissertação (Mestrado em Desenho Industrial) - Universidade Estadual Paulista.

MOREIRA, J.R.C. Relatório setorial preliminar : moda. FINEP, 2007. Disponível em: <http://www.finep.gov.br/PortalDPP/relatorio_setorial>. Acesso em: jun. 2009.

NAPOLI, Sylvio. Diferenciação do produto: estratégia da indústria têxtil para enfrentar a concorrência estrangeira. Inovação Uniemp, Campinas, v. 3, n. 3, p. 9. mai./jun. 2007. Entrevista concedida a Patrícia Mariuzzo.

PIRES, Dorotéia Baduy. Design de moda: olhares diversos. Barueri-SP: Estação das Letras e Cores, 2008.

PINHEIRO, Daniela. Cópia + imita + plagia = roupa nova. Revista Piauí, São Paulo, ano 1, n. 9, p. 34-38, jun. 2007. 
QUEIROZ, Carlos Alberto Ramos Soares de. Manual de terceirização: onde podemos errar no desenvolvimento e na implantação dos projetos e quais são os caminhos do sucesso. São Paulo: STS, 1998.

ROMEIRO FILHO, Eduardo. Projeto do produto: apostila do curso de Engenharia de Produção UFMG. 7. ed. Belo Horizonte: LIDEP/DEP/EE/UFMG, 2004.

SANCHES, Maria Celeste de Fátima. Projetando moda: diretrizes para a aconcepção de produtos. In: PIRES, Dorotéia Baduy (Org.). Design de moda: olhares diversos. São Paulo: Estação das Letras e Cores, 2008. p. 289 - 301.

SEMPRINI. Andrea. A marca pos-moderna: poder e fragilidade da marc ana sociedade contemporânea. Tradução de Elisabeth Leone. 2. ed. Sao Paulo: Estacao das Letras e Cores, 2010.

SOUZA, Patrícia de Mello. A modelagem tridimensional como implemento do processo de desenvolvimento do produto de moda. Bauru, 2006. 113 f. Dissertação (Mestrado em Desenho Industrial) - Universidade Estadual Paulista.

SUONO, Celso Tetsuro. O desenho técnico do vestuário sob a ótica do profissional da área de modelagem . Bauru, 2007. 135 f. Dissertação (Mestrado em Desenho Industrial) Universidade Estadual Paulista.

YIN, Robert K. Estudo de caso: planejamento e métodos. 2.ed. Porto Alegre: Bookman, 2001. 